\title{
The effect of the enrichment of bread with fibres from fava bean husk by-products on postprandial satiety response and palatability
}

\author{
D. Daliani ${ }^{1}$, S. Stott ${ }^{1}$, A. Fiore ${ }^{1}$ and S. Cottin ${ }^{1}$ \\ ${ }^{1}$ Division of Food and Drink, Abertay University, Dundee, DD1 1 HG
}

Consumption of dietary fibre (DF) may promote satiety and reduce the risk of many diseases, including heart diseases, diabetes and bowel cancer ${ }^{(1)}$. Despite current recommendations, DF consumption remains too low, possibly due to a lower sensory acceptance of fibre enriched products ${ }^{(2)}$. Fava Bean Husks (FBHs) are a by-product of fava beans (FBs), currently used for livestock feed. They are high in fibre ${ }^{(1)}$ and could become a sustainable way of increasing the fibre content in staple food in Scotland ${ }^{(3)}$. The aim of this research was to identify the impact of FBHs on satiety (Study 1) and consumer palatability and acceptance (Study 2), in a healthy young population.

Study 1 was a crossover randomised controlled trial $(\mathrm{RCT})(\mathrm{n}=21 ; 10$ males, 11 females) comparing the satiating effect of two iso-caloric plain bread breakfasts: 33\% FBH enriched bread (FBB1) and control white bread (WB), providing $9.17 \mathrm{~g}$ and $2.12 \mathrm{~g}$ of DF per $100 \mathrm{~g}$ of bread, respectively. Hunger ratings were measured on Visual Analog Scales (VAS) at baseline and over $2 \mathrm{~h}$ after bread consumption. Study $2(\mathrm{n}=68 ; 42$ males, 22 females, 4 N/A) compared the palatability and consumer acceptance (colour, crumb appearance, crust appearance, odour/aroma, texture, flavour, after-taste, overall impression and purchase possibility) of FBB1, FBB2 (37\% FBHs, $9.80 \mathrm{~g} \mathrm{DF} / 100 \mathrm{~g})$, WB and two supermarket, white (SB1) and wholemeal (SB2) breads, in random order, using the 9-Point Hedonic Scale (9-PHS).

In study 1, FBB1 decreased hunger $(p=0.046)$, increased fullness $(p=0.031)$ and decreased the desire to eat $(p=0.033)$ compared to the WB (Figure 1), while the appetite score ([hunger + desire to eat + prospective consumption +100 - fullness] / 4) was decreased without reaching significance $(p=0.07)$. There was no gender difference. In Study 2, the overall impression, flavour and after-taste were lower in FBB1 and FBB2 compared to WB, while texture was only rated lower in FBB2 (Table 1).

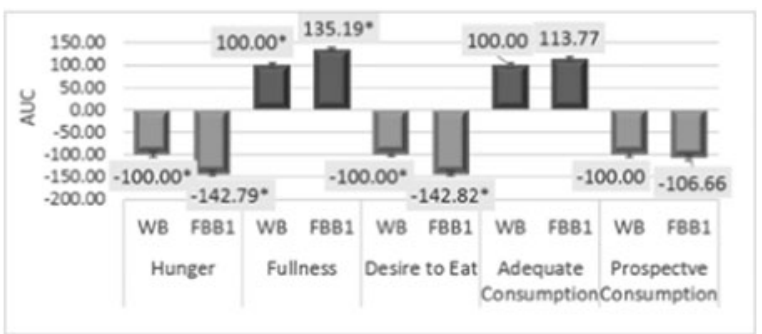

Fig. 1. Mean areas under the curve (AUCs) of each satiety VAS score (SE) between FBB1 and WB (*p $<0.05$; Wilcoxon test).

Table 1. Mean 9-PHS VAS values (SE) for the sensory appeal of attributes between FBB1, FBB2, WB, SB1 and SB2 (*indicates a significant difference between the breads $(p<0.05$; Friedman test); different superscripts in the same row indicate a significant difference between groups, $p<0.05$; Wilcoxon test).

\begin{tabular}{|c|c|c|c|c|c|c|c|c|c|c|}
\hline & $S B 1$ & $S E$ & $S B 2$ & $S E$ & $W B$ & $S E$ & $F B B 1$ & $S E$ & $F B B 2$ & $S E$ \\
\hline Colour* & $6.46^{\mathrm{a}, \mathrm{b}}$ & 0.03 & $6.90^{\mathrm{a}}$ & 0.02 & $6.26^{\mathrm{b}}$ & 0.03 & $5.93^{\mathrm{b}}$ & 0.02 & $6.00^{\mathrm{b}}$ & 0.03 \\
\hline Curmb Appearance* & $6.28^{\mathrm{a}, \mathrm{b}}$ & 0.03 & $6.73^{\mathrm{a}}$ & 0.02 & $6.24^{\mathrm{a}, \mathrm{b}}$ & 0.03 & $6.18^{\mathrm{b}}$ & 0.03 & $5.82^{\mathrm{b}}$ & 0.03 \\
\hline Crust Appearance* & $6.76^{\mathrm{a}}$ & 0.03 & $6.67^{\mathrm{a}, \mathrm{b}}$ & 0.02 & $6.40^{\mathrm{b}, \mathrm{c}}$ & 0.03 & $6.19^{\mathrm{a}, \mathrm{c}}$ & 0.03 & $6.04^{\mathrm{c}}$ & 0.03 \\
\hline OdourlAroma* & $6.78^{\mathrm{a}}$ & 0.03 & $6.45^{\mathrm{a}, \mathrm{b}}$ & 0.03 & $6.01^{\mathrm{b}, \mathrm{c}}$ & 0.03 & $5.68^{\mathrm{c}}$ & 0.03 & $5.80^{\mathrm{c}}$ & 0.03 \\
\hline Texture* & $6.45^{\mathrm{a}, \mathrm{b}, \mathrm{a}}$ & 0.03 & $6.53^{\mathrm{b}, \mathrm{c}}$ & 0.02 & $6.50^{\mathrm{c}}$ & 0.03 & $5.95^{\mathrm{a}, \mathrm{b}}$ & 0.03 & $5.77^{\mathrm{a}, \mathrm{c}}$ & 0.03 \\
\hline Flavour* & $6.45^{\mathrm{a}}$ & 0.03 & $6.10^{\mathrm{a}}$ & 0.03 & $6.18^{\mathrm{a}, \mathrm{c}}$ & 0.03 & $5.31^{\mathrm{b}}$ & 0.03 & $5.48^{\mathrm{b}, \mathrm{c}}$ & 0.03 \\
\hline After-Taste* & 6.54 & 0.03 & $5.78^{\mathrm{a}}$ & 0.03 & $6.06^{\mathrm{a}}$ & 0.03 & $5.03^{b}$ & 0.03 & $5.17^{\mathrm{b}}$ & 0.03 \\
\hline Overall Impression* & $6.35^{\mathrm{a}}$ & 0.03 & $6.33^{\mathrm{a}}$ & 0.03 & $6.24^{\mathrm{a}}$ & 0.03 & $5.31^{\mathrm{b}}$ & 0.03 & $5.43^{\mathrm{b}}$ & 0.03 \\
\hline Purchase Possibility* & $6.16^{\mathrm{a}}$ & 0.03 & $5.85^{\mathrm{a}}$ & 0.03 & $6.01^{\mathrm{a}}$ & 0.03 & $4.55^{\mathrm{b}}$ & 0.03 & $4.90^{\mathrm{b}}$ & 0.03 \\
\hline
\end{tabular}

The results show that FB by-products present the potential to enrich staple foods with fibres ( $>9 \mathrm{~g} / 100 \mathrm{~g})$ and increase postprandial satiety. Whether reduced hunger is associated with a reduced subsequent energy intake, as previously demonstrated ${ }^{(4)}$, remains to be established. This may provide a cost effective way to increase fibre intake in the Scottish population. Further research is needed to prevent the slight but significant decrease in consumer acceptance often associated with fibre enrichment of foods ${ }^{(2)}$.

1. Lunn J, Buttriss JL (2007) Nutr Bull 32(1), 21-64.

2. Grigor JM, Brennan CS, Hutchings SC et al. (2016) Int J Food Sci Tech 51(1), 3-13.

3. Iriti M, Varoni EM (2017) Int J Mol Sci 18(2), 1-6.

4. Howarth NC, Saltzman E, Roberts SB (2001) Nutr Rev 59(5), 129-39. 